\title{
Resistive Index for the Evaluation of Renal Damage in Diabetes Mellitus Type 2
}

\author{
Diyan Genov¹, Atanas Kundurdgiev¹, Ventsislava Pencheva ${ }^{2 *}$ \\ ${ }^{1}$ Clinic of Nephrology, UMHAT “St. Ivan Rilski”, Medical University Sofia, Sofia, Bulgaria \\ ${ }^{2}$ Clinic of Pulmology, Department of Internal Medicine, UMHAT “Alexandrovska”, Medical University Sofia, Sofia, Bulgaria \\ Email: *pencheva.bg@abv.bg
}

How to cite this paper: Genov, D., Kundurdgiev, A. and Pencheva, V. (2018) Resistive Index for the Evaluation of Renal Damage in Diabetes Mellitus Type 2. Open Journal of Internal Medicine, 8, 160-166. https://doi.org/10.4236/ojim.2018.82016

Received: May 16, 2018

Accepted: June 18, 2018

Published: June 21, 2018

Copyright $\odot 2018$ by authors and Scientific Research Publishing Inc. This work is licensed under the Creative Commons Attribution International License (CC BY 4.0).

http://creativecommons.org/licenses/by/4.0/

\begin{abstract}
Background: One of the most common causes of renal impairment and development of chronic kidney disease is diabetes mellitus type 2 (DM 2). The aim of this prospective study was to determine the role of Resistive Index (RI) as a non-invasive marker for the evaluation of renal impairment in patients with DM 2. Material and Methods: 47 patients with DM 2 in mean age 62.66 \pm 10.081 years were included in the study for the period of one year. All of them were with well-compensated diabetes mellitus $(\mathrm{HbAlc}<7.0 \%)$ and optimal control of arterial hypertension. Hematological analysis of blood were carried out. Serum and urine biochemical parameters were tested, glomerular filtration rate (GFR) was calculated, and abdominal ultrasound with measure of RI was done. Results: Patients with RI $<0.7$ and those with $\mathrm{RI} \geq 0.7$ did not differ significantly in terms of their age, sex, body mass index (BMI), duration of DM 2 and arterial hypertension, use of antihypertensive drugs and HbA1c ( $p>0.05$ for all). There was significant difference between the groups according to serum creatinine ( $p=0.026)$, GFR $(p=0.044)$ and the degree of proteinuria $(\mathrm{p}=0.001)$. There was a positive correlation between $\mathrm{RI}$ and serum creatinine $(r=0.418 ; p=0.001)$ and between RI and proteinuria $(r=$ 0.396; $p=0.004)$. A negative correlation relationship between RI and GFR values was found $(\mathrm{r}=-0.413 ; \mathrm{p}=0.011)$. Conclusions: $\mathrm{RI}$ may be used as an indicator for the assessment of the severity of renal impairment in patients with DM 2. It correlates well with serum creatinine, GFR and proteinuria, which are proven biochemical parameters indicating the degree of renal damage in patients with DM 2.
\end{abstract}

\section{Keywords}

Diabetes Mellitus Type 2, Resistive Index, Serum Creatinine, Proteinutia, Glomerular Filtration Rate 


\section{Introduction}

One of the most common causes of renal impairment and the development of chronic kidney disease is diabetes mellitus type 2 (DM 2) [1]. Around 20\%-40\% of patients with DM 2 and microalbuminuria have progression of renal damage and are diagnosed with nephropathy about 20 years after the onset of diabetes. Approximately $20 \%$ of them develop end-stage renal disease (ESRD) [2]. Microalbuminuria and proteinuria can be considered as important signs of the progression of glomerular abnormalities [3]. Ather kidney function measures, such as estimated glomerular filtration rate (GFR) and serum creatinine are used as markers to assess mortality risk or to predict these outcomes in kidney disease [4].

The resistive index of an artery (RI) is a hemodynamic measure considered to reflect its vascular impedance [5]. Higher resistive index values consist in a manifestation of local arteriolopathy [6]. Evaluation of vascular impedance at different sites of the renal parenchyma may suggest functional or structural changes within the kidneys and could provide useful diagnostic and prognostic information [7]. Elevated RI is associated with adverse outcomes in different diseases like diabetes mellitus or hypertension [4].

The aim of the study was to establish the role of RI as a non-invasive marker for the evaluation of renal damage in patients with DM 2.

\section{Material and Methods}

\subsection{Patients}

47 patients with DM 2, hospitalized in Clinic of nephrology, University Hospital "St. Ivan Rilski", Sofia, from February 2017 to March 2018 were enrolled in this prospective study. The mean age of the patients was $62.66 \pm 10.081$ years. The male-to-female ratio was $21 / 26$ ( $44.7 \%$ men and $55.3 \%$ women). Written informed consent was obtained from the participants. The protocols conformed to the guidelines of the 1975 Helsinki Declaration. All patients were with well controled DM 2 and without history of any other renal diseases. 36 of participants (76.6 \%) were with anamnesis for arterial hypertension on medical treatment. Patients younger than 18 years old, oncology or systemic diseases, glycated haemoglobin $(\mathrm{HbAlc})>7.0 \%$ or suboptimal control of arterial hypertension (Blood pressure $>140 / 90 \mathrm{mmHg}$ ) were excluded [8].

\subsection{Testing Procedures}

All patients were clinically examined and body mass index (BMI) was calculated.

Hematological analysis and tests of serum glucose, $\mathrm{HbAlc}$, serum creatinine, blood urea nitrogen, albumin, electrolytes, total cholesterol, triglyceride, lowdensity lipoprotein cholesterol (LDL), very low-density lipoprotein (VLDL), and high-density lipoprotein cholesterol (HDL) were done. 24-hour urine samples were obtained for proteinuria. GFR was calculated using Cockroft-Gault formula $(140-$ age $) \times($ weight in $\mathrm{kg}) /($ serum creatinine $\times 72) \times(0.85$ for women $)$ for all 
patients and later adjusted by body surface [9].

\subsection{Doppler Ultrasonography}

Doppler ultrasound was performed using an ultrasound machine Prosound Alpha 7 (Hitachi Aloka Medical, Ltd., Tokyo, Japan) in all subjects. RI was measured in each kidney and mean RI value was obtained for each patient by averaging the two kidneys' mean RI values. The RI was determined as follows: RI = $(\mathrm{PSV}-\mathrm{EDV}) / \mathrm{PSV}$ where: $\mathrm{PSV}=$ peak systolic flow velocity, $\mathrm{EDV}=$ end-diastolic flow velocity. Values of RI higher than 0.70 were considered pathological [10].

\subsection{Statistical Analysis}

The statistical analysis was performed using SPSS version 16. A variational analysis of the quantitative variables was used, as well as the Fisher's exact test, the method of Kolmogorov-Smirnov and the method of Mann-Whitney. Regression analysis was applied to establish the relationship between dependent variable RI and other analyzed variables as independent variables. A value of $p \leq 0.05$ was considered statistically significant.

\section{Results}

According to the RI index all subjects were divided into two groups. Group 1 consisted of 19 patients with normal RI values (RI $<0.7)$. Group $2(n=28)$ had elevated values of $\mathrm{RI} \geq 0.7$. The main demographic and laboratory data of both groups were shown in Table 1.

There was no significant difference between the groups according to sex, age, BMI, duration of DM 2 and HbAlc ( $p>0.05$ for all). The systolic and diastolic blood pressure were similar in two groups ( $p>0.05$ for both). There was no statistical difference in the presence of arterial hypertension. 13 (68.4\%) patients in Group 1 were with anamnesis of high blood pressure compared to 23 (82.1\%) patients in Group $2(\mathrm{p}=0.312)$. Duration of the disease was similar $(13.71 \pm 8.94$ years vs. $17.33 \pm 10.86$ years, $p=0.499$ ). The use of antihypertensive drugs was not different in patients with $\mathrm{RI}<0.7$ than those with $\mathrm{RI} \geq 0.7$ ( $\mathrm{p}>0.05$ for all) (Table 2).

There were no significant differences in the haematology, serum glucose, blood urea nitrogen, albumin, total cholesterol, triglyceride, LDL, VLDL, HDL and electrolytes (data not shown). The significantly higher serum creatinine and lower GFR were found in the group with RI $\geq 0.7$ ( $p<0.05$ for all) (Table 1 ). The serum creatinine in Group 1 was $94.26 \pm 21.512 \mu \mathrm{mol} / \mathrm{l}$ and mean GFR calculated for this group was $77.80 \pm 28.25 \mathrm{ml} / \mathrm{min} / 1.73 \mathrm{~m}^{2}$. In Group 2 serum creatinine was $165.04 \pm 34.603 \mu \mathrm{mol} / \mathrm{l}$ and GFR was $50.13 \pm 14.60 \mathrm{ml} / \mathrm{min} /$ $1.73 \mathrm{~m}^{2}$.

The prouteinuria was significantly higher in patients with $\mathrm{RI} \geq 0.7(\mathrm{p}=0.001)$ (Table 1). Five patients in Group 1 had albuminuria less than $30 \mathrm{mg} / 24 \mathrm{~h}$ and 11 patients were with albuminuria between $30-299 \mathrm{mg} / 24 \mathrm{~h}$. In this group only 3 
patients were with greater than $300 \mathrm{mg}$ of urinary albumin excretion in 24 hours. In comparison, among patients in Group 2 only one patient had albuminuria $<30 \mathrm{mg} / 24 \mathrm{~h}$ and another one was with urinary albumin excretion in 24 hours between $30-299 \mathrm{mg}$. The most patients $(\mathrm{n}=26)$ in the Group 2 had proteinuria $\geq 300 \mathrm{mg} / 24 \mathrm{~h}$.

Linear regression analyses were performed to examine the relationship between the RI values with serum creatinine, proteinuria and GFR (Table 3). A strongly positive correlation was found between RI and serum creatinine $(\mathrm{r}=$ $0.418 ; \mathrm{p}=0.001)$. There was a positive correlation between RI and proteinuria as well $(r=0.396, p=0.004)$. The same analysis found negative correlation between RI and GFR $(r=-0.413, p=0.011)$.

Table 1. Demographics of groups according to the Resistive Index.

\begin{tabular}{cccc}
\hline & $\begin{array}{c}\text { Group } 1 \\
\mathrm{~N}=19\end{array}$ & $\begin{array}{c}\text { Group } 2 \\
\mathrm{~N}=28\end{array}$ & $\mathrm{p}$ \\
\hline Male & $7(36.8 \%)$ & $14(50 \%)$ & 0.551 \\
Age (yrs) & $61.58 \pm 8.572$ & $63.39 \pm 11.080$ & 0.389 \\
BMI & $29.90 \pm 6.395$ & $30.34 \pm 3.687$ & 0.862 \\
$\begin{array}{c}\text { Diabetes duration } \\
\text { (months) }\end{array}$ & $97.95 \pm 57.56$ & $135.21 \pm 100.81$ & 0.246 \\
$\begin{array}{c}\text { HbAlc (\%) } \\
\text { Systolic blood pressure } \\
\text { (mmHg) }\end{array}$ & $121.05 \pm 9.94$ & $125.60 \pm 14.87$ & 0.919 \\
$\begin{array}{c}\text { Diastolic blood pressure } \\
(\mathrm{mmHg})\end{array}$ & $77.95 \pm 11.26$ & $81.77 \pm 13.24$ & 0.187 \\
$\begin{array}{c}\text { Creatinine } \mu \mathrm{mol} / 1 \\
\text { Proteinuria g/24h }\end{array}$ & $94.26 \pm 21.512$ & $165.04 \pm 34.603$ & 0.346 \\
$\begin{array}{c}\text { GFR ml/min/1.73m } \\
\text { (m) }\end{array}$ & $0.8947 \pm 0.258$ & $1.8929 \pm 0.416$ & $0.026^{*}$ \\
\hline
\end{tabular}

Data are expressed as mean \pm standard deviation $(\mathrm{SD})$ and number (percent). Statistical analysis: Fisher's exact test, method of Mann-Whitney. ${ }^{*}$ p-value with statistic significant difference.

Table 2. Antihypertensive drugs of groups according to the Resistive Index.

\begin{tabular}{cccc}
\hline Antihypertensive drugs & $\begin{array}{c}\text { Group 1 } \\
\mathrm{N}=19\end{array}$ & $\begin{array}{c}\text { Group 2 } \\
\mathrm{N}=28\end{array}$ & $\mathrm{p}$ \\
\hline ACEIs & $9(47.4 \%)$ & $12(42.9 \%)$ & 0.775 \\
ARBs & $3(15.8 \%)$ & $6(21.4 \%)$ & 0.720 \\
CCBs & $5(26.3 \%)$ & $13(46.4 \%)$ & 0.226 \\
beta-blockers & $5(26.3 \%)$ & $15(53.6 \%)$ & 0.079 \\
Diuretics & $4(21.1 \%)$ & $11(39.3 \%)$ & 0.220 \\
Alpha-blockers & $1(5.3 \%)$ & $6(21.4 \%)$ & 0.215 \\
\hline
\end{tabular}

Data are given as n (\%). Statistical analysis: Fisher's exact test. ACEIs, angiotensin converting enzyme inhibitors; ARBs, angiotensin-receptor blockers; CCBs, calcium channel blockers. 
Table 3. Relationship between the RI values with serum creatinine, proteinuria and GFR.

\begin{tabular}{ccc}
\hline & \multicolumn{2}{c}{$\mathrm{RI}$} \\
\cline { 2 - 3 } & $\mathrm{r}$ & $\mathrm{p}$ \\
\hline serum creatinine & 0.418 & $0.001^{\star}$ \\
proteinuria & 0.396 & $0.004^{\star}$ \\
GFR & -0.413 & $0.011^{\star}$
\end{tabular}

Statistical analysis: Linear regression analyses. ${ }^{*} \mathrm{p}$-value with statistic significant difference.

\section{Discussion}

The RI increases in various kidney diseases and a lot of studies have shown the associations between RI, renal function and patient prognosis [7] [11]. The most studies agree that RI 0.70 should be the upper limit of normal intrarenal vascular resistance and higher values are associated with different renal pathologies [3].

Renal pathological changes in DM2 are as a result of atherosclerosis of the intra and extra renal arteries in a combination of microangiopathy of the glomerular capillaries, afferent arterioles and efferent arterioles. Renal RI is tightly related to renal arteriolosclerosis and most studies show that RI is increased in DM2 [12]. According to some authors the severity of renal damage correlates well with the increasing of RI [12] [13].

In our study 28 of all patients are with increased RI. On the other hand only 19 of patients with DM 2 included in the study are with RI $<0.7$. We find significantly higher serum creatinine in patients with $\mathrm{RI} \geq 0.7$ than in other group $(165.04 \pm 34.603 \mu \mathrm{mol} / \mathrm{l}$ vs. $94.26 \pm 21.512 \mu \mathrm{mol} / \mathrm{l}, \mathrm{p}=0.026)$. Strongly positive correlation between RI and serum creatinine $(r=0.418 ; p=0.001)$ that we observe is prove by previous studies [14] [15]. For example Sari et al. reports higher correlation $(\mathrm{r}=0.84)$ between serum creatinine and RI values in diabetic nephropathy [16].

According to our results there is a positive correlation between RI and proteinuria. Most of the patients with $\mathrm{RI} \geq 0.7$ are with significant proteinuria ( $\geq 300$ $\mathrm{mg} / 24 \mathrm{~h}$ ) while in the other group patients are with proteinuria $<300 \mathrm{mg} / 24 \mathrm{~h}$ predominantly. The increase in proteinuria is associated with an increase in the RI $(r=0.396, p=0.004)$. Our results are comparable to a similar study conducted [17] [18]. Ishimura et al. found that patients with diabetic nephropathy and increased values of albuminuria and serum creatinine have increased RI values although statistical significance was not reached [19]. In Milovanceva-Popovska et al. study proteinuria was associated with increased RI indicating nephropathy though this relation was not statistically significant until follow up after 3 and 6 months and further decline in creatinine clearance [13]. Shirin et al. also observed positive correlation between RI with albuminuria $(\mathrm{r}=0.725, \mathrm{p}<$ $0.01)$ [14].

We find that patients with $\mathrm{RI}<0.7$ have significantly lower GFR than patients with $\mathrm{RI} \geq 0.7\left(77.80 \pm 28.25 \mathrm{ml} / \mathrm{min} / 1.73 \mathrm{~m}^{2}\right.$ vs. $50.13 \pm 14.60 \mathrm{ml} / \mathrm{min} / 1.73 \mathrm{~m}^{2}, \mathrm{p}$ 
$=0.044)$. Negative correlation is found between RI and GFR $(\mathrm{r}=-0.413, \mathrm{p}=$ 0.011). Our results are similar to those received by MacIsaac et al. They also find negative relationship between GFR and RI [20]. Parolini et al. establish that initial RI correlates with final GFR $(r=-0.4, p<0.001)$ [21]. Another authors observe the same relationship [3] [17].

\section{Study Limitations}

The current study has several limitations. First, the number of cases is small. No follow-up of patients is performed in the study, and the change in the RI over time is not assessed. This will be the subject of further research.

\section{Conclusion}

RI may be used as an indicator for assessing the severity of renal damage in patients with DM 2. It correlates correctly with serum creatinine, GFR and proteinuria, which are proven biochemical parameters showing the extent of renal impairment in patients with DM 2.

\section{References}

[1] World Health Organization (2016) Global Report on Diabetes: Executive Summary. http://www.who.int/diabetes/global-report

[2] Aldukhayel, A. (2017) Prevalence of Diabetic Nephropathy among Type 2 Diabetic Patients in Some of the Arab Countries. International Journal of Health Sciences, 11, 1-4.

[3] Amer, M.S., Farid, T.M., Adly, N.N., Mohammed, G.S., Omar, O.H., et al. (2016) Value of Renal Resistance Index in Detection of Diabetes Mellitus Complications in Egyptian Elderly Indian. Journal of Applied Research, 6, 51-54.

[4] Toledo, C., Thomas, G., Schold, J.D., Arrigain, S., Gornik, H.L., Nally, J.V., et al. (2015) Renal Resistive Index and Mortality in Chronic Kidney Disease. Hypertension, 66, 382-388. https://doi.org/10.1161/HYPERTENSIONAHA.115.05536

[5] Staub, D., Meyerhans, A., Bundi, B., Schmid, H.P. and Frauchiger, B. (2006) Prediction of Cardiovascular Morbidity and Mortality: Comparison of the Internal Carotid Artery Resistive Index with the Common Carotid Artery Intima-Media Thickness. Stroke, 37, 800-805. https://doi.org/10.1161/01.STR.0000202589.47401.c6

[6] Berni, A., Boddi, M., Fattori, E.B., Cecioni, I., Berardino, S., et al. (2010) Serum Uric Acid Levels and Renal Damage in Hyperuricemic Hypertensive Patients Treated with Renin-Angiotensin System Blockers. American Journal of Hypertension, 23, 675-680. https://doi.org/10.1038/ajh.2010.33

[7] Hanamura, K., Tojo, A., Kinugasa, S., Asaba, K. and Fujita, T. (2012) The Resistive Index Is a Marker of Renal Function, Pathology, Prognosis, and Responsiveness to Steroid Therapy in Chronic Kidney Disease Patients. International Journal of Nephrology, 2012, 139565. https://doi.org/10.1155/2012/139565

[8] (2015) American Diabetes Association Standards of Medical Care in Diabetes-2015. Diabetes Care, 38, S1-S94.

[9] Cockcroft, D.W. and Gault, M.H. (1976) Prediction of Creatinine Clearance from Serum Creatinine. Nephron, 16, 31-41. https://doi.org/10.1159/000180580

[10] Knapp, R., Plötzeneder, A., Frauscher, F., Helweg, G., Judmaier, W., et al. (1995) 
Variability of Doppler Parameters in the Healthy Kidney: An Anatomic-Physiologic Correlation. Journal of Ultrasound in Medicine, 14, 427-429. https://doi.org/10.7863/jum.1995.14.6.427

[11] Sugiura, T. and Wada, A. (2011) Resistive Index Predicts Renal Prognosis in Chronic Kidney Disease: Results of a 4-Year Follow-Up. Clinical and Experimental Nephrology, 2011, 114-120. https://doi.org/10.1007/s10157-010-0371-3

[12] Afsar, B. and Elsurer, R. (2017) Increased Renal Resistive Index in Type 2 Diabetes: Clinical Relevance, Mechanisms and Future Directions. Diabetes \& Metabolic Syndrome, 11, 291-296. https://doi.org/10.1016/j.dsx.2016.08.019

[13] Milovanceva-Popovska, M. and Dzikova, S. (2007) Progression of Diabetic Nephropathy: Value of Intrarenal Resistive Index (RI). Prilozi, 28, 69-79.

[14] Shirin, M., Sharif, M.M., Gurung, A. and Datta, A. (2015) Resistive Index of Intrarenal Artery in Evaluation of Diabetic Nephropathy. Bangladesh Medical Research Council Bulletin, 41, 125-130. https://doi.org/10.3329/bmrcb.v41i3.29888

[15] Galesic, K., Sabljar-Matovinovic, M., Tomic, M. and Brkljacic, B. (2004) Renal Vascular Resistance in Glomerular Diseases-Correlation of Resistance Index with Biopsy Findings. Collegium Antropologicum, 28, 667-674.

[16] Sari, A., Dinc, H., Zibandeh, A., Telatar, M. and Gümele, H.R. (1999) Value of Resistive Index in Patients with Clinical Diabetic Nephropathy. Investigative Radiology, 34, 718-721. https://doi.org/10.1097/00004424-199911000-00008

[17] Abdelhamid Yasser, M., Fawzy Marie, W., Abd Al-Salam Randa, F., Gouda Yousra, M. and Salem Mona, M. (2017) Relation between Resistivity and Pulsatility Indices of Renal and Intrarenal Arteries and Degree of Albuminuria in Type 2 Diabetic Patients. Kasr Al Ainy Medical Journal, 23, 1-5.

[18] Afsar, B. and Elsurer, R. (2012) Comparison of Renal Resistive Index among Patients with Type 2 Diabetes with Different Levels of Creatinine Clearance and Urinary Albumin Excretion. Diabetic Medicine, 29, 1043-1046. https://doi.org/10.1111/j.1464-5491.2012.03593.x

[19] Ishimura, E., Nishizawa, Y., Kawagishi, T., Okuno, Y., Kogawa, K., et al. (1997) Intrarenal Hemodynamic Abnormalities in Diabetic Nephropathy Measured by Duplex Doppler Sonography. Kidney International, 51, 1920-1927. https://doi.org/10.1038/ki.1997.261

[20] MacIsaac, R.J., Panagiotopoulos, S., McNeil, K.J., Smith, T.J., Tsalamandris, C., et al. (2006) Is Nonalbuminuric Renal Insufficiency in Type 2 Diabetes Related to an Increase in Intrarenal Vascular Disease? Diabetes Care, 29, 1560-1566. https://doi.org/10.2337/dc05-1788

[21] Parolini, C., Noce, A., Staffolani, E., Giarrizzo, G.F., Costanzi, S., et al. (2009) Renal Resistive Index and Long-Term Outcome in Chronic Nephropathies. Radiology, 252, 888-896. https://doi.org/10.1148/radiol.2523080351 